\title{
Disseminated Mycobacterium tuberculosis complex infection in a girl with partial dominant IFN- $\gamma$ receptor 1 deficiency
}

\author{
MAEGORZATA PAC ${ }^{\prime}$, JACINTA BUSTAMANTE ${ }^{2,3}$, PIOTR BUDA ${ }^{4}$, ANNA WIETESKA-KLIMCZAK ${ }^{4}$, \\ JERZY ZIOEKOWSKI ${ }^{5}$, MARIA KRASIŃSKA ${ }^{6}$, BOŻENA LIPKA ${ }^{7}$, MAJA KLAUDEL-DRESZLER', \\ JEAN-LAURENT CASANOVA ${ }^{2,8}$, BARBARA PIĄTOSA ${ }^{9}$, ANNA KAMINSSKA ${ }^{10}$, EWA BERNATOWSKA ${ }^{l}$
}

\author{
${ }^{1}$ Department of Immunology, Children's Memorial Health Institute, Warsaw, Poland \\ ${ }^{2}$ Laboratory of Human Genetics of Infectious Diseases, Necker Branch, Institut National de la Sante et de la Recherche Medicale, \\ U980, Univerisity Paris Descartes, Necker Medical School, Paris, France \\ ${ }^{3}$ Center for the Study of Primary Immunodeficiencies, AP-HP, Necker Hospital, 75015 Paris, France \\ ${ }^{4}$ Department of Pediatrics, Children's Memorial Health Institute, Warsaw, Poland \\ ${ }^{5}$ Department of Allergy and Pulmonology, Medical University, Warsaw, Poland \\ ${ }^{6}$ Department of Tuberculosis and Lung Disease, Mazovian Center for Tuberculosis and Lung Disease, Otwock, Poland \\ ${ }^{7}$ Department of Infant's Diseases, Children's Memorial Health Institute, Warsaw, Poland \\ ${ }^{8}$ St. Giles Laboratory of Human Genetics of Infectious Diseases, Rockefeler Branch, The Rockefeller University, New York, NY, USA \\ ${ }^{9}$ Histocompatibility Laboratory, Children's Memorial Health Institute, Warsaw, Poland \\ ${ }^{10}$ Department of Scintigraphy, Children's Memorial Health Institute, Warsaw, Poland
}

\begin{abstract}
We describe here a girl who was vaccinated at birth with BCG (Bacillus Calmette-Guérin) vaccine according to national immunization schedule in Poland. After the age of 2.5 m.o., she developed disseminated BCG infection. Primary immunodeficiencies (PID), such as severe combined immunodeficiency (SCID), chronic granulomatous disease (CGD), hyper IgM syndrome (HIGM), hyper IgE syndrome (HIES) were excluded. The diagnostic tests exploring IFN- $\gamma / I L-12$ axis were performed. The 818del4, the most common basis of IFNGRI deficiency was found.
\end{abstract}

Key words: BCG, IFNGR, osteomyelitis, primary immunodeficiency.

(Centr Eur J Immunol 2012; 37 (4): 378-381)

\section{Introduction}

Immunocompromised hosts such as children suffering from primary immunodeficiencies (PID) or HIV-infected individuals are especially prone to complications from Bacillus Calmette-Guérin (BCG) vaccine or environmental mycobacteria (EM). Numerous cases of severe combined immunodeficiency (SCID) patients who developed disseminated BCG disease have been reported in association with overhelming or life-threatening infections, such as bacterial, viral, or fungal [1-3]. There are also some reports on mycobacterial infections in patients with chronic granulomatous disease (CGD), hyper-IgM syndrome (HIGM) or hyper-IgE syndrome (HIES) [3-5]. In late 80's and 90's of the past century the new group of rare congenital primary immunodeficiency syndromes conferring a predisposition to infections caused by mycobacteria was described - Mendelian susceptibility to mycobacterial diseases (MSMD). Affected individuals are prone to infections caused especially by weakly virulent mycobacteria such as BCG-vaccine or EM. They are also susceptible to more virulent mycobacteria such as Mycobacterium tuberculosis [6-12]. In contrast to other PID the vast majority of MSMD patients is resistant to other microbial infections. However in up to $50 \%$ of them systemic salmonellosis - nontyphoidal is reported [1].

Six autosomal genes $[I F N G R 1-$ interferon $\gamma$ receptor 1 , IFNGR2 - interferon $\gamma$ receptor 2, STAT1 - signal trans-

Correspondence: Małgorzata Pac, Department of Immunology, Children's Memorial Health Institute, Al. Dzieci Polskich 20, 04-730 Warsaw, Poland, phone: +48 2281573 78, fax: +48 2281573 82, e-mail: malgorzata.pac@wp.pl 
ducer and activator of transcription $1, I L 12 R B 1-\beta 1$ chain shared by receptors for interleukin (IL)-12 and IL-23, IL12B - p40 subunit shared by IL-12 and IL-23, IRF8-interferon regulatory factor 8 ] and two X-linked genes (NEMO nuclear factor- $\kappa \mathrm{B}$-essential modulator and $C Y B B$ cytochrome $\mathrm{b} \beta$ chain) were identified for MSMD group $[1,7,9,10,14]$. They display a high level of genetic and allelic heterogeneity, with known mutations in 8 genes accounting for existance of 15 distinct mendelian traits and diseases.

Inherited IFN- $\gamma$ R 1 deficiency was the first genetic etiology of MSMD to be identified [1, 7, 11, 15]. The highest degree of allelic heterogeneity confers IFNGR1 with four different diseases in IFNGR1 complete deficiency with or without surface expression of receptor or partial deficiency which can display autosomal recessive (AR) or autosomal dominant (AD) inheritance $[1,7,12,13,15]$. The most common deficiency in IFNGR1 is caused by dominant IFNGR1 mutation, a microdeletion $818 \mathrm{del} 4$ [1, 11, 15]. This microdeletion results in the introduction of a premature stop codon into the proximal intracellular domain. The cytoplasmic domain is truncated and lacks the motifs required for signal transduction (Janus kinase-1 and Stat1) and recycling, resulting in the abundant expression of a dominant negative nonfunctional truncated IFN- $\gamma$ receptor on the cell surface, with no signal transduction $[16,17]$. Clinically, the patients suffer from BCG or EM diseases, specially osteomyelitis [1, 3, 11-13]. Sporadically infections caused by intracellular bacteria such as Nocardia and Listeria, intracellular pathogens such as Leishmania and Histoplasma capsulatum or some viruses like Herpes virus- 8 are encountered [7, 11, 18].

We present the case of a girl without remarkable history with generalized BCG infection and heterozygous mutation in IFNGRI gene.

\section{Case report}

The patient was born in Poland in 2010 to unrelated, healthy and young parents. The child was given BCG vaccine containing Brazilian strain (Biomed, Poland), as well as hepatitis B vaccine at birth, according to the national immunization program $[19,20]$. Two months later she received next vaccines against tetanus, pertussis, diphtheria, poliomyelitis, Haemophilus influenzae and hepatitis B. At the age of 3 months, the girl was admitted to the Children's Memorial Health Institute in Warsaw, Poland, due to rash, enlarging axillary nodule, located close to BCG vaccination site since the age of 2.5 months old, accompanied by fever and limitation of upper limb movements, that were observed shortly before admission. No remarkable family and perinatal history was revealed.

At admission, the general condition of girl was poor. She presented with generalized rash, inflexible tumor of the diameter $5 \mathrm{~cm}$, in the region of left axilla. The liver and spleen were markedly enlarged. Her upper left limb movements were limited and seem to be painful. Laboratory tests revealed the presence of an inflammatory process with leukocytosis at $51 \times 10^{9} / 1$ (normal range: $4-10 \times 10^{9} / 1$ ), with a differential of $42 \%$ neutrophils, $35 \%$ lymphocytes, $11 \%$ eosinophils, C-reactive protein $-5.34 \mathrm{mg} / \mathrm{dl}$ (normal range $<0.5 \mathrm{mg} / \mathrm{dl}$ ), fibrinogen $-4.64 \mathrm{~g} / \mathrm{l}$, erythrocyte sedimentation rate $-55 \mathrm{~mm} / \mathrm{hour}$. She was found to have anemia with hemoglobin of $7.5 \mathrm{~g} / \mathrm{dl}$, slightly prolonged international normalized ratio (INR - 1.48) without any other clotting abnormal tests and normal platelet account. The blood cultures, as well as nose, throat, urine were negative. The chest X-ray showed parenchymal infiltration and atelectasis of the right lung. Diagnosis of osteomyelitis was done on the basis of bone X-rays of left femur and left humerus, confirmed by scintigraphy (Fig. 1). Abdominal ultrasonography revealed lymphadenopathy and focal lesions in the spleen. A gastric aspirate was taken at three times and polymerase chain reaction (PCR) was positive for DNA of M. tuberculosis complex in one of them. A course of anti-tuberculous drugs (isoniazid, rifampicin) was administered immediately and further antibiotics (clarithromycin, amikacin, ciprofloxacin) were added consecutively for the next 6 months. The resolution of fever, lesions in the spleen and improvement of child's general condition were obtained. Elevated inflammatory parameters persisted. Despite such therapeutic management, that caused some improvement at the beginning of the therapy, the progressive infiltration of axillary lymph nodes with enterocutaneous fistula was observed during next 4-6 weeks. The child was seen several times by pneumonologist and phthisiologist. Surgical debridement and drainage were finally performed. Additional analyses of gastric aspirates and material from fistula as well as from a lymph node were done. Acid-fast stain showed mycobacteria belonging to $M$. tuberculosis complex specimen in fistula smear and lymph node biopsy. Polymerase chain reaction was also positive in the smear from fistula and lymph node. Quantiferon-TB Gold test (Cellestis) - simple blood test to identify M. tuberculosis, alternative to the Tuberculin Skin Test, was negative. No positive cultures were obtained from all provided materials. Cerebrospinal fluid analysis, magnetic resonance of brain, computed tomography of chest did not reveal any features of ongoing infection. Streptomycin and pyrazinamide were added to the previous therapy with the gradual resolution of changes of lymph nodes and fistula. Due to the history of BCG vaccine, the suspicion of PID complicated by disseminated BCG infection were suspected. Initial immunological assessment encompassing serum immunoglobulins concentration (IgG, IgA, IgM, IgE), complement C3, C4 levels, lymphocyte subsets and lymphoproliferation tests were found to be normal, except for a mild decrease of CD8+ percentage, but absolute count was within the normal ranges. Respiratory burst test for NADPH oxidase activity in polymorphonuclear cells stimulated with forbol esther, TCR expression, CD127, CD40 repeated several times did not 

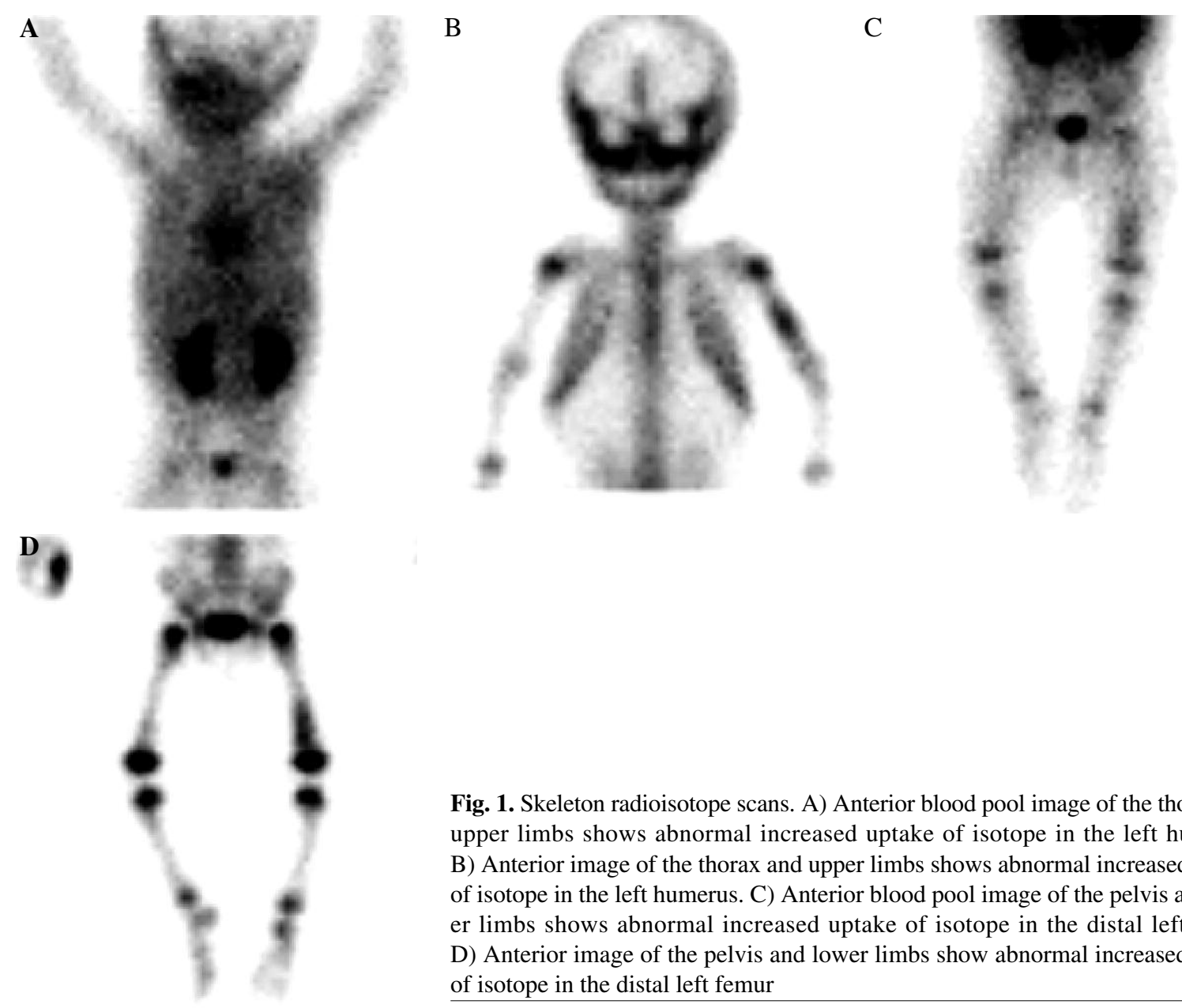

Fig. 1. Skeleton radioisotope scans. A) Anterior blood pool image of the thorax and upper limbs shows abnormal increased uptake of isotope in the left humerus. B) Anterior image of the thorax and upper limbs shows abnormal increased uptake of isotope in the left humerus. C) Anterior blood pool image of the pelvis and lower limbs shows abnormal increased uptake of isotope in the distal left femur. D) Anterior image of the pelvis and lower limbs show abnormal increased uptake of isotope in the distal left femur

confirm the suspicion of CGD, SCID, or HIGM syndromes. Additional immunological work-up revealed normal expression of CD212 on activated T lymphocytes and NK cells and no defects of Fc $\gamma$ RIII expression on NK cells, as measured by Leu11a and Leu11c binding. Although almost all monocytes expressed CD119, the median fluorescence of CD119 was highly elevated in comparison to normal control.

A blood sample from the patient and healthy control was stimulated with live BCG with and without IL-12 and IFN- $\gamma$. Normal production of IFN- $\gamma$ was observed in the supernatants and by ELISA. However a little amount of IL-12 was produced after BCG + IFN- $\gamma$ activation. None trace of IFN- $\gamma$ was detected in the plasma by ELISA.

Molecular investigation showed microdeletion 818del4, indicating a partial autosomal dominant defect of IFNGR1. Both parents were wild type for this mutation. The child's condition significantly improved and of fistula closed after 10 weeks of the treatment. Both rifampicin and isoniasid were maintained for 2 years until mid March 2012. Since then she has not undergone any further antituberculosis treatment.

\section{Discussion}

We describe here a Polish patient suffering from disseminated $M$. tuberculosis complex infection documented on a basis of bacterioscopy and PCR technics, without positive cultures. The child was vaccinated within the first 24 hours of her life with BCG vaccine and hepatitis B, according to mandatory immunization program in Poland [19-21]. The diagnostic process let detect a heterozygous 818 del4 deletion in IFNGR1. It is known to be the most common mutation underlying IFNGR1 deficiency $[1,7,12$, 15]. Mutations in this gene were the first to be identified as the cause of MSMD. A 4 base pair deletion at nucleotide position 818 (818del4) was found in 11 of unrelated kindreds $[16,17]$. This mutation leads to a premature stop codon at position 827-829 within the intracellular domain of the receptor. The receptor is expressed on the cell surface but the mutant receptor lacks the three motifs required for intracellular signaling (the JAK3 and STAT1 binding sites, and the tyrosine phosphorylation site). It also lacks a recycling motif so the truncated receptor accumulates on the cell surface and interferes with signaling by the normal 
receptor encoded by the normal copy of IFNGR1. Thus the mutant allele has a dominant effect. Dominant IFNGR1 deficiency was described for the first time in 1999. Up to now over 60 cases have been reported [1].

The clinical course of the disease is usually less severe compared to complete IFNGR1 deficiency. The general prognosis is fairly good $[1,7]$. In most cases the disease is controlled by prolonged antibiotic treatment. The IFN- $\gamma$ therapy is recommended in mycobacterial and disseminated infections, in addition of ATB in some cases $[1,12]$. Our patient was treated with six antituberculous antibiotics, with no need of IFN- $\gamma$ treatment.

In conclusion it must be said that children inoculated with BCG vaccine at birth with BCG-osteomyelitis and/or severe axillary lymphadenopathy should be considered as a PID patients, and in case of no evidence of classic PID as MSMD, especially partial dominant IFNGR1 deficiency should be taken into account. Patients affected with disseminated BCG infection should be treated with combination of antituberculous antibiotics for at least 2 years.

The authors declare no conflict of interest.

\section{References}

1. Al-Muhsen S, Casanova JL (2008): The genetic heterogeneity of mendelian susceptibility to mycobacterial diseases. J Allergy Clin Immunol 122: 1043-1051.

2. Santos A, Dias A, Cordeiro A, et al. (2010): Severe axillary lymphadenitis after BCG vaccination: alert for primary immunodeficiencies. J Microbiol Immunol Infect 43: s530-537.

3. Lee WI, Huang JL, Yeh KW, et al. (2011): Immune defects in active mycobacterial diseases in patients with primary immunodeficiency diseases (PIDs). J Formos Med Assoc 110: 750758.

4. Galkina E, Kondratenko I, Bologov A (2007): Mycobacterial infections in primary immunodeficiency patients. Adv Exp Med Biol 601: 75-81.

5. Bustamante J, Aksu G, Vogt G, et al. (2007): BCG-osis and tuberculosis in a child with chronic granulomatous disease. J Allergy Clin Immunol 120: 32-38.

6. Casanova JL, Abel L (2002): Genetic dissection of immunity to Mycobacteria: the human model. Annu Rev Immunol 20: 581-620.

7. Filipe-Santos O, Bustamante J, Chapgier A, et al. (2006): Inborn errors of IL-12/23 and IFN $\gamma$-mediated immunity: molecular, cellular, and clinical features. Semin Immunol 18: 347-361.

8. Boisson-Dupuis S, El Baghdadi J, Parvaneh N, et al. (2011): IL-12R $\beta 1$ deficiency in two of fifty children with severe tuberculosis from Iran, Morocco, and Turkey. PLoS One 6: e18524.

9. Bustamante J, Arias AA, Vogt G, et al. (2011): Germline CYBB mutations that selectively affect macrophages in kindreds with $\mathrm{X}$-linked predisposition to tuberculous mycobacterial disease. Nat Immunol 12: 213-221.

10. Hambleton S, Salem S, Bustamante J, et al. (2011): IRF8 mutations and human dendritic-cell immunodeficiency. N Engl J Med 365: 127-138.
11. Caragol I, Casanova J-L (2003): Inherited disorders of the Interleukin-12/Interferon-gamma axis: Mendelian predisposition to mycobacterial disease in man. Immunologia 3: 263276.

12. Dorman SE, Picard C, Lammas D, et al. (2004): Clinical features of dominant and recessive interferon- $\gamma$ receptor deficiencies. Lancet 364: 2113-2121.

13. Prando C, Boisson-Dupuis S, Grant AV, et al. (2010): Paternal uniparental isodisomy of chromosome 6 causing a complex syndrome including complete interferon- $\gamma$ receptor 1 deficiency. Am J Med Genet A 152A: 622-629.

14. Bustamante J, Picard C, Boisson-Dupuis S, et al. (2011): Genetic lessons learned from X-linked Mendelian susceptibility to mycobacterial diseases. Ann N Y Acad Sci 1246: $92-$ 101.

15. Jouanguy E, Lamhamedi-Cherradi S, Lammas D, et al. (1999): A human INFGR1 small deletion hotspot associated with dominant susceptibility to mycobacterial infections. Nat Genet 21: 370-378.

16. Sasaki Y, Nomura A, Kusuhara K, et al. (2002): Genetic basis of patients with bacille Calmette-Guérin osteomyelitis in Japan: identification of dominant partial interferon receptor 1 deficiency as a predominant type. J Infect Dis 185: 706-709.

17. Villella A, Picard C, Jouanguy E, et al. (2001): Recurrent Mycobacterium avium osteomyelitis associated with a novel dominant interferon gamma receptor mutation. Pediatrics 107: e47.

18. Kong XF, Vogt G, Chapgier A, et al. (2010): A novel form of cell type-specific partial IFN- $\gamma$ R 1 deficiency caused by a germ line mutation of the IFNGR1 initiation codon. Hum Mol Genet 19: 434-444.

19. Ustawa z dnia 5 grudnia 2008 r. O zapobieganiu oraz zwalczaniu zakażeń i chorób zakaźnych u ludzi (Dz.U. z 2008 r., Nr 234, poz. 1570)

20. Załącznik do Komunikatu Głównego Inspektora Sanitarnego z dnia 14 marca 2006 r. w sprawie Programu Szczepień Ochronnych na 2006 r.

21. Barańska-Rybak W, Kozicka D, Lange M, et al. (2011): Swimming pool granuloma - difficult diagnostic problem. Post Dermatol Alergol 28: 406-411. 